\title{
Characterization of in-plane backbone response of cold-formed steel beams
}

\author{
Deniz AYHAN', Benjamin W. SCHAFER 2
}

\begin{abstract}
Thin-walled cold-formed steel beams are investigated with existing experimental data and shell finite element simulations to characterize their in-plane moment-rotation behavior, up to and past peak strength, in local or distortional failure modes. Although ultimate strength prediction of cold-formed steel members is generally well addressed in design codes, pre- and post-peak member stiffness is only partially addressed; while member ductility and post-peak momentrotation response suffers from a lack of any clear guidance. Without fundamental information on cold-formed steel moment-rotation/curvature response, i.e. the backbone curve, system modeling for cold-formed steel structures to collapse remains severely hampered. Existing data on coldformed steel beams are used as the basis for the study conducted herein. Simplified momentrotation models, motivated from ASCE 41 characterizations, defined with pre-peak flexural rigidity degradation, post-peak plateau and strength drop are explored by equating the area under the backbone moment-rotation response (energy) between the available data and simplified models. In-plane response of cold-formed steel beams is parametrized with new design expressions depending on local and distortional cross-section slenderness. This research provides work for potential incorporation into design standards such as ASCE 41 and AISI S100. Out-ofplane response of cold-formed steel beams, including lateral-torsional buckling, remains as needed future work.
\end{abstract}

Keywords: cold-formed steel beams, local buckling, distortional buckling, moment-rotation, moment-curvature, backbone curve, cross-section slenderness. 


\section{Introduction}

Collapse analysis of a building comprised of load bearing cold-formed steel framing, whether for static loads, wind loads, progressive collapse, or seismic design is predicated on knowledge of the nonlinear response of the components and connections that make up the building. After one member yields determination of the force or moment redistribution in a cold-formed steel (CFS) building system may not be accurately completed with current knowledge, requiring current design to ignore system effects. Given that CFS cross-sections are typically locally slender they have a potentially complex moment-rotation response.

Potential failure mechanisms of a CFS beam include yielding, local buckling, distortional buckling, lateral-torsional buckling, and combinations thereof. Here we focus only on in-plane, or laterally-braced behavior, thus lateral-torsional buckling is excluded. For modelling CFS structures to collapse, particularly under dynamic (seismic) loads, no current method provides guidance on member ductility and moment-rotation response for members. This in part leads to overly conservative design philosophies; for example, in CFS framed buildings all nonlinearity is assumed to be concentrated in pre-tested connections at the shear walls and any contribution from the steel framing is ignored.

This research attempts to provide needed information on the stiffness and ductility of CFS beams and provides a method for parameterizing the beam response depending on cross-section slenderness. CFS beams subjected to cross-section deformations resulting from both local and distortional buckling are examined. The paper, in Section 2, begins by introducing existing experimental data and shell finite element models on cold-formed steel beams. This is followed 
in Section 3 by an introduction to simplified multi-linear models for moment-rotation response, motivated primarily from ASCE 41. Section 4 summarizes recent work of the authors characterizing the pre-peak response (strength and stiffness) as a function of cross-section slenderness. Section 5 provides detailed results for characterizing the post-peak moment-rotation response as a function of cross-section slenderness in either local or distortional buckling and examines the accuracy of the developed expressions. Section 6 discusses the developed method and highlights the ability of the expressions to capture CFS beam behavior ranging from slender, with little post-peak response, to stocky with considerable inelastic yielding and ductility. This discussion is followed by conclusions and acknowledgments.

\section{Cold-formed steel beam behavior - existing data and design methods}

For the design of typical lipped channel (C) and lipped zee (Z) CFS beams, local and distortional cross-section buckling modes must be considered in addition to lateral-torsional buckling. Even for laterally-braced beams the in-plane behavior still must consider the potential interaction between yielding, local, and distortional buckling. Here we focus on existing experiments $[3,4]$ and shell finite element (FE) analysis [5] of laterally-braced beams failing in elastic and inelastic local and distortional buckling.

The experiments on local and distortional buckling of CFS beams by Yu and Schafer [3,4] are utilized herein. Paired CFS beams composed of industry standard C and Z specimens varying from 92 to $305 \mathrm{~mm}$ deep and from 1.09 to $2.46 \mathrm{~mm}$ thick were tested in 4 point bending. In the first series of tests the setup, as shown in Figure 1, was designed to allow local buckling failures while restricting distortional buckling through careful attachment of a panel to the compression 
flange. In the second series, the distortional buckling tests, the panel remained in the shear spans only and no restraint was provided to the compression flange of the specimens in the moment region. In these second series of tests distortional buckling failures occurred. Lateral-torsional buckling and twist were restricted in the tests by pairing the specimens at supports and load application points. In total, 24 of the local buckling tests and 22 of the distortional buckling tests from Yu and Schafer $[3,4]$ were employed in this study for characterization of the in-plane beam response.

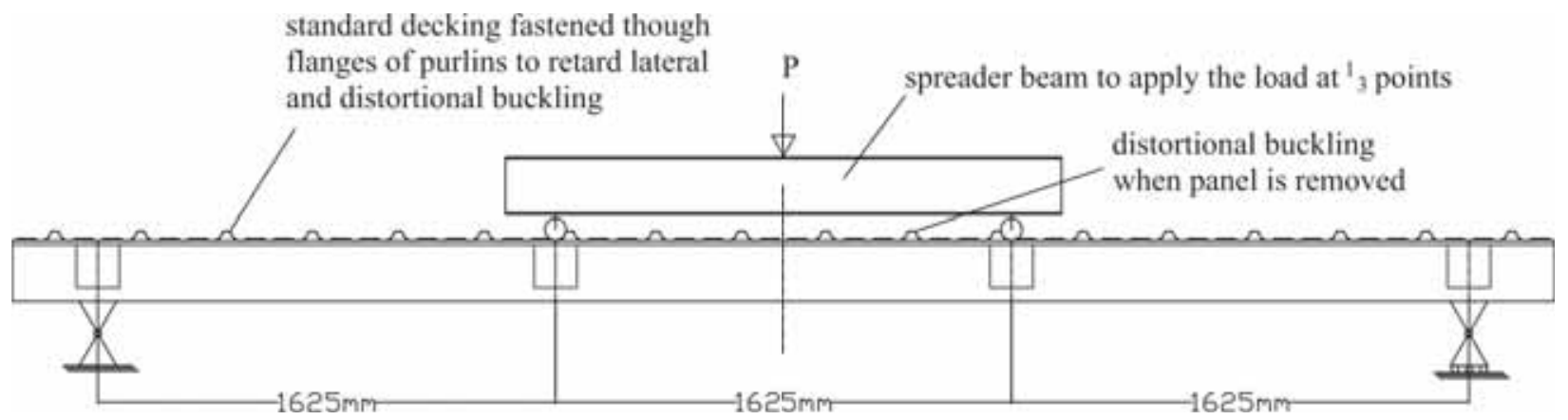

Figure 1. Elevation view of overall test arrangement for four point bending test

Shifferaw and Schafer [5] used the experiments of Yu and Schafer [3,4] to develop and validate an ABAQUS [6] nonlinear collapse shell finite element (FE) model focusing on inelastic local and distortional buckling limit states in typical C and Z CFS sections. The goal of their analyses was not to recreate the tests, but rather to provide an idealized model that could consistently provide local and distortional buckling failure modes in a computationally efficient manner. The developed model includes only the central $1.63 \mathrm{~m}$ constant moment region from the tests and employs special boundary conditions at the ends (no end section distortion and warping fixity) and along the flanges (nodal point-braced at mid-width of the compression flange for local, 
unbraced for distortional). Centerline dimensions from seventeen cross-sections from Yu and Schafer $[3,4]$ were selected. From these centerline dimensions the thickness was varied from 1.37 to $3.42 \mathrm{~mm}$, resulting in 187 different models.

The moment capacity of beams is known to be sensitive to the cross-section slenderness $(\lambda)$ which is defined as the following for local (subscript $l$ ) and distortional (subscript $d$ ) slenderness:

$$
\begin{aligned}
& \lambda_{l}=\sqrt{\frac{M_{y}}{M_{c r l}}} \\
& \lambda_{d}=\sqrt{\frac{M_{y}}{M_{c r d}}}
\end{aligned}
$$

where $M_{y}$ is the elastic yield moment, and $M_{c r}$ is the elastic critical buckling moment either in local $(l)$ or distortional $(d)$ buckling. Peak strength observed in the tests and FE models correlates well with cross-section slenderness and the independently determined Direct Strength Method (DSM) design expressions for local and distortional buckling [1] as shown in Figure 2. Note, the FE modeling focused on CFS sections that can develop inelastic reserve; i.e., sections with a peak bending capacity greater than the moment at first yield. 


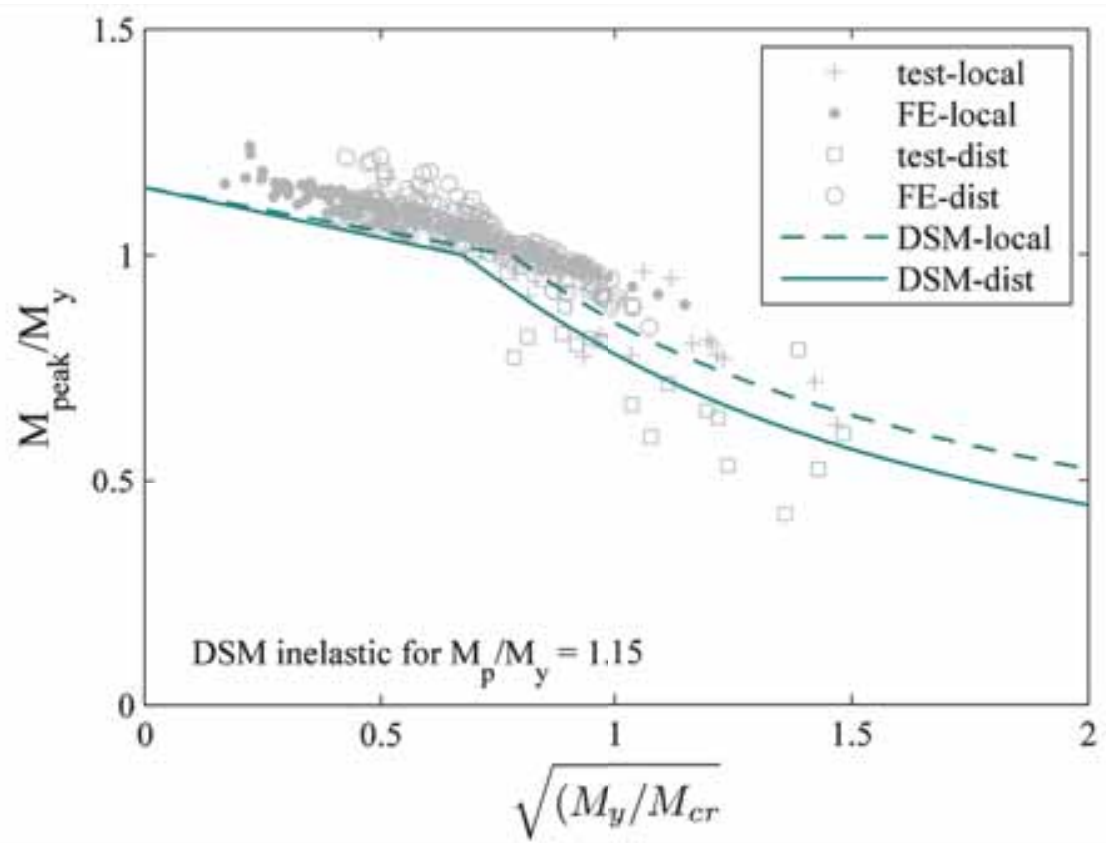

Figure 2. Correlation of peak moment prediction with DSM (Note: every cross-section has a unique $\mathrm{M}_{\mathrm{p}} / \mathrm{M}_{\mathrm{y}}$, this influences the inelastic reserve strength prediction, average $\mathrm{M}_{\mathrm{p}} / \mathrm{M}_{\mathrm{y}}$ for studied sections is approximately is 1.15 , strength is only shown for this value.)

As Figure 2 illustrates, local and distortional cross-sectional slenderness are adequate explanatory variables for parameterizing the peak moment strength of CFS members, and are directly utilized by design specifications [2]. In addition to peak strength, the authors have recently provided new closed-form expressions to predict the pre-peak bending stiffness [7]. The proposed expressions also utilize cross-section slenderness as the explanatory variable and adequately predict the available data as well as provide a significant improvement for bending stiffness prediction when compared to current methods. However, post-peak behavior and ductility, i.e. the full moment-rotation characterization, remains unaddressed. 


\section{Multi-linear models to represent CFS member moment-rotation behavior}

The ductile performance of steel structures benefits greatly from the ability of its members to dissipate energy by means of hysteretic behavior. For a beam the amount of dissipated energy is correlated with the area under the moment-rotation curve. In this section, simplified momentrotation curves selected by equating the area under the backbone moment-rotation response between available data and simplified multi-linear models are explored. Equivalent Energy Elastic Plastic models [8] with both pre-peak bilinear and trilinear shapes were explored, but rejected due to their inability to include post-peak moment degradation [9]. To include observed response, where in some cases significant post-peak degradation occurs over a relatively small range of rotation, models motivated from ASCE 41 [10] are examined for characterizing CFS beam behavior.

\subsection{Characterization of backbone response by ASCE 41 methods}

The latest in a series of documents developed to assist engineers with the seismic assessment and rehabilitation of existing buildings [11,12] is ASCE 41 [10] where three basic types of component force-deformation curves are utilized as shown in Figure 3, where $\mathrm{Q}=\mathrm{P}$ or $\mathrm{M}$ and $\Delta=\Delta$ or $\theta$. The acceptance criteria for each type is defined depending on the performance level.

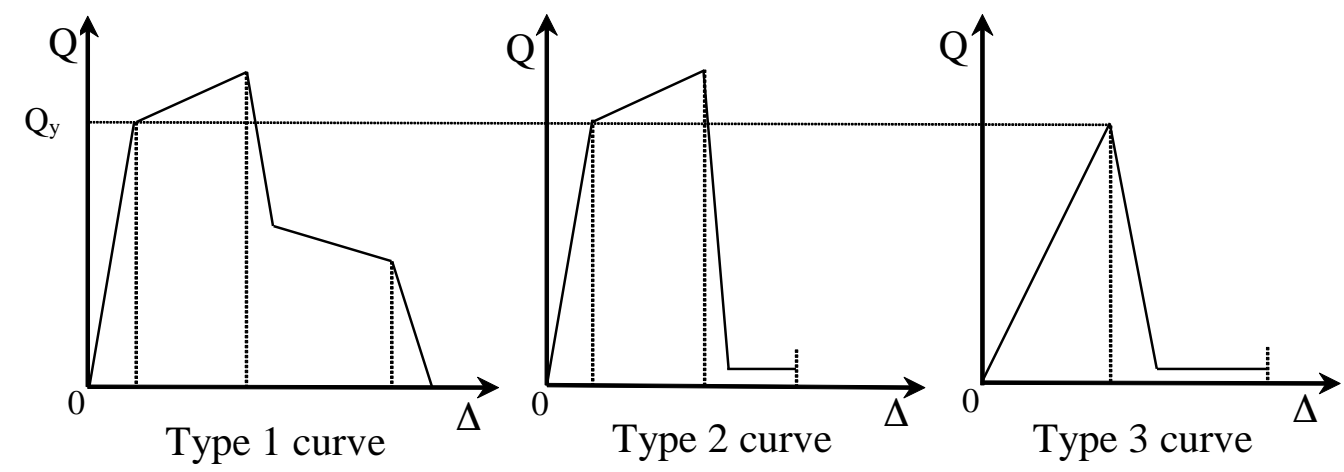


Figure 3. Component force-deformations curves of ASCE 41 [10].

ASCE 41 does not include explicit predictions for CFS members; therefore, an objective of this work is to create ASCE 41 consistent backbone curves for CFS members. The area under the $M$ $\theta$ curve and the shape of the $M-\theta$ curve are used as the two key characteristics for matching the ASCE 41 models to the available data. The Type 1 curve (Figure 3) was selected as best able to represent the behavior of CFS beams given its ability to capture post-peak moment loss as well as reduced stiffness in the pre-peak range. However, the usual Type 1 curve must be modified for CFS members. For CFS pre-peak stiffness loss may be due to cross-section deformations (e.g. local buckling), the peak can be less than the first yield capacity, and the post-peak behavior may not degrade in the same fashion as the Type 1 curve.

\subsection{Simplified backbone response model}

A simplified variant of the Type 1 response is selected, as illustrated in Figure 4. The parameters, that are necessary to characterize these models include: $M_{1}$ the peak (fully effective) elastic moment, $k_{1}$ the elastic stiffness, $M_{2}$ the peak moment, $k_{2}$ the tangent stiffness between the elastic and the peak point, $\Delta \theta$ the (largely inelastic) rotation step after the peak point, $\Delta M$ the moment drop after the peak point, and $\theta_{4}$ the maximum rotation. Modest variants on this basic model were also explored, as reported in [13].

Fit of the model was measured by minimizing the error between the pre-peak, and post-peak energy (area under the $M-\theta$ curve) between that of the Type 1 (Figure 4) model and the selected tests [3,4] or FE model simulations [5] and was completed in MATLAB [14]. The existing tests and FE models have limited post-peak information in some cases, and were not specifically 
created for assessing post-peak response. The available post-peak data is limited to that greater than or equal to $50 \%$ of the peak moment. In addition, the model fit is sensitive to initial conditions; ultimately, the initial conditions were selected such that the initial stiffness $\left(k_{1}\right)$, peak moment $\left(M_{2}\right)$, and final rotation $\left(\theta_{4}\right)$ match the available data exactly [13] and error minimization provided the solution for the additional model parameters $\left(M_{1}, k_{2}, \Delta \theta\right.$, and $\left.\Delta M\right)$. Error residuals in the energy fits are found to be reasonable, generally less than $1 \times 10^{-10}$ (kip-in $)^{2}\left(1.3 \times 10^{-12}\right.$ in $\left.(\mathrm{kNm})^{2}\right)$. Therefore, adoption of Figure 4 is recommended; hereinafter referred to as the modified Type 1 model.

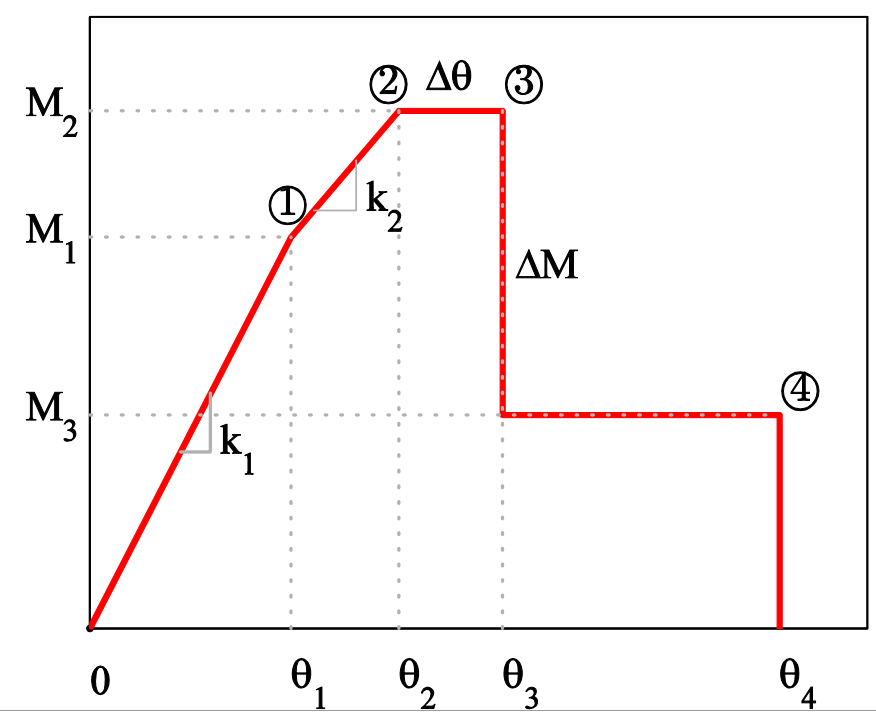

Figure 4. The parameters of modified Type 1 model.

Using the test and FE model data, the simplified curves have been generated with all parameters for all studied sections. These results are than used herein to obtain simplified design expressions for $\Delta \theta, \Delta \mathrm{M}$, etc. Design expressions for pre-peak curve is done in [7] and presented in the next section. Design expressions for post-peak are the focus of this paper and presented for local buckling in Section 5.1 and for distortional buckling in Section 5.2. 


\section{Design expressions for pre-peak flexural rigidity prediction}

A prediction method for rotation and moment, up to the peak moment, has recently been developed by the authors [7]. Correlation with the appropriate local or distortional cross-section slenderness $\left(\lambda_{1}\right.$ or $\left.\lambda_{d}\right)$ is used to define simple design expressions for the fully effective moment $M_{1}$, peak moment $M_{2}$, and the coinciding rotations $\theta_{1}$ and $\theta_{2}$ as provided in Table 1 .

Table 1. Design expressions to predict cold-formed steel member pre-peak behavior

\begin{tabular}{|c|c|c|}
\hline \multicolumn{2}{|r|}{ Local buckling } & Distortional buckling \\
\hline$\frac{M_{1}}{M_{y}}=$ & $\left\{\begin{array}{cl}1 & \text { if } \lambda_{l}<0.650 \\
\left(\frac{0.650}{\lambda_{l}^{2}}\right)^{2} & \text { if } \lambda_{l} \geq 0.650\end{array}\right.$ & $\left\{\begin{array}{cl}1 & \text { if } \lambda_{d}<0.60 \\
\left(\frac{0.60}{\lambda_{d}^{2}}\right)^{2} & \text { if } \lambda_{d} \geq 0.60\end{array}\right.$ \\
\hline$\frac{\theta_{1}}{\theta_{y}}=$ & $\frac{M_{1}}{M_{y}}$ & $\frac{M_{1}}{M_{y}}$ \\
\hline$\frac{M_{2}}{M_{y}}=$ & $\begin{cases}1+\left(1-\frac{1}{C_{y l}^{2}}\right) \frac{\left(M_{p}-M_{y}\right)}{M_{y}} & \text { if } \lambda_{l}<0.776 \\
\left(1-0.15\left(\frac{1}{\lambda_{l}^{2}}\right)^{0.4}\right)\left(\frac{1}{\lambda_{l}^{2}}\right)^{0.4} & \text { if } \lambda_{l} \geq 0.776\end{cases}$ & $\begin{cases}1+\left(1-\frac{1}{C_{y d}^{2}}\right) \frac{\left(M_{p}-M_{y}\right)}{M_{y}} & \text { if } \lambda_{d}<0.673 \\
\left(1-0.22\left(\frac{1}{\lambda_{d}^{2}}\right)^{0.5}\right)\left(\frac{1}{\lambda_{d}^{2}}\right)^{0.5} & \text { if } \lambda_{d} \geq 0.673\end{cases}$ \\
\hline$\frac{\theta_{2}}{\theta_{y}}=$ & $\frac{1}{\lambda_{l}} \geq \frac{M_{2}}{\theta_{y} k_{e}}$ & $\left(\frac{1}{\lambda_{d}}\right)^{1.4} \geq \frac{M_{2}}{\theta_{y} k_{e}}$ \\
\hline
\end{tabular}

where $M_{y}$ is the yield moment, $M_{p}$ is the plastic moment, $C_{y}$ is the compression strain factor for local and distortional buckling ( $C_{y l}=\sqrt{0.776 / \lambda_{l}} \leq 3$ and $C_{y d}=\sqrt{0.673 / \lambda_{d}} \leq 3$ ) and $k_{\mathrm{e}}$ is the elastic rotation stiffness.

The moment-rotation response can be converted into moment-curvature response, noting that.

$$
\kappa=\frac{1}{\rho}=\frac{M}{E I}
$$


where $M$ is the bending moment, $E$ the modulus of elasticity, and $I$ the cross-section moment of inertia. Our intent here is to provide solutions for engineers that use beam elements to predict deflection as common in design. Therefore, the assumption is concentrated plasticity and reductions similar to plastic hinge analysis. So appropriately normalized, the ratios of curvature and rotation to yield form equalities:

$$
\begin{aligned}
& \frac{\kappa_{1}}{\kappa_{y}}=\frac{\theta_{1}}{\theta_{y}} \\
& \frac{\kappa_{2}}{\kappa_{y}}=\frac{\theta_{2}}{\theta_{y}}
\end{aligned}
$$

Accordingly, the maximum $\left(E I_{g}\right)$ and minimum $\left(E I_{\min }\right)$ flexural rigidities may be defined as.

$$
\begin{gathered}
E I_{g}=\frac{M_{1}}{\kappa_{1}} \\
E I_{\text {min }}=\frac{M_{2}}{\kappa_{2}}
\end{gathered}
$$

Where $E I_{\min }$ is the secant flexural rigidity at the peak. Accordingly, the secant stiffness reduction may be predicted by determining the effective moment of inertia between $I_{g}$ and $I_{\min }$ as depicted in Figure 5 where $\mathrm{M}_{1}$ and $\mathrm{M}_{2}$ are defined as given in Table 1.

$$
I_{e}=\left\{\begin{array}{cc}
I_{g} & \text { if } M \leq \mathrm{M}_{1} \\
\frac{I_{g}\left(M_{2}-M\right)+I_{\text {min }}\left(M-M_{1}\right)}{M_{2}-M_{1}} & \text { if } \mathrm{M}_{1} \leq M \leq \mathrm{M}_{2} \\
I_{\text {min }} & \text { if } M=\mathrm{M}_{2}
\end{array}\right.
$$




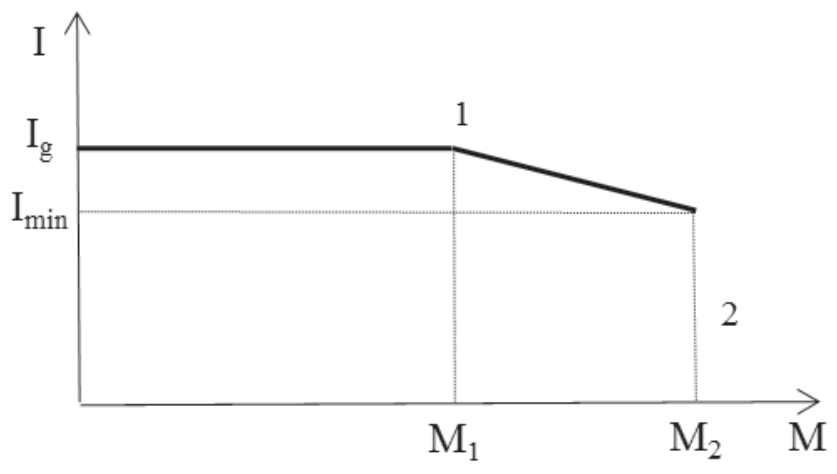

Figure 5. Normalized bending stiffness prediction with moment increase.

The relation between the prediction of the reduced stiffness and the applied moment for the selected tests and FE models is provided in Figures 6 and 7 for local buckling and distortional buckling, respectively. The mean and standard deviation of observed-to-predicted ratios of prepeak energy, peak moment, flexural rigidity, and rotation at peak moment are calculated for the tests and FE models as shown in Table 2. The reduction correlates reasonably well with the observed data, and better than available methods [7].

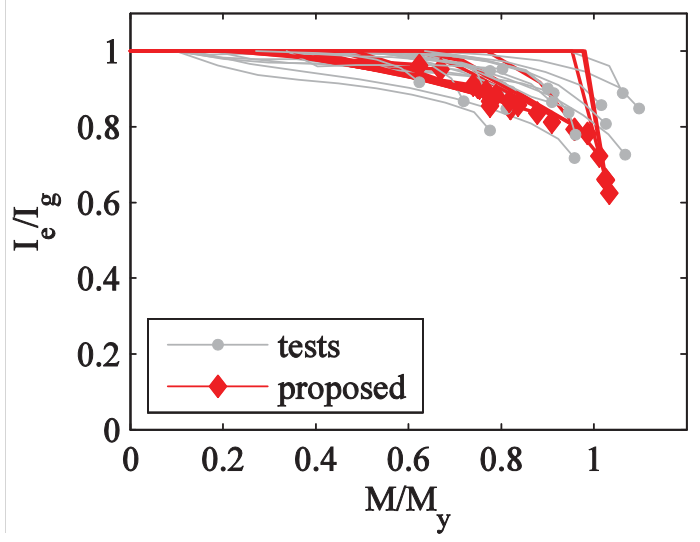

a. Tests

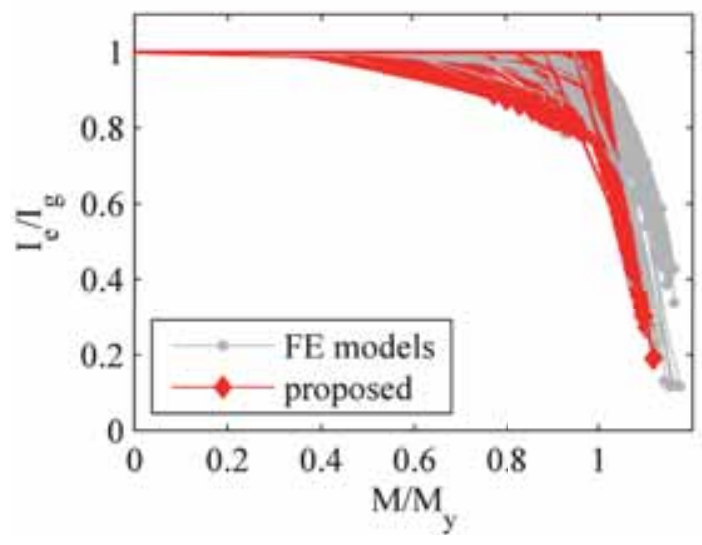

b. FE models

Figure 6. Accuracy of proposed bending stiffness prediction for local buckling 

a. Tests
b. FE models

Figure 7. Accuracy of proposed bending stiffness prediction for distortional buckling

Table 2. Test-to-predicted statistics for the pre-peak predictions

\begin{tabular}{|c|c|c|c|c|c|c|}
\hline & & & \multicolumn{4}{|c|}{ ratios of observed-to-predicted for } \\
\hline & & & energy & $M_{2}$ & $\mathrm{~K}_{2}$ & $E I_{\min }$ \\
\hline \multirow{8}{*}{$\begin{array}{c}\text { local } \\
\text { bucklin } \\
\mathrm{g}\end{array}$} & \multirow{3}{*}{ tests } & $\mathrm{n}$ & 23 & 23 & 23 & 23 \\
\hline & & $\mu$ & 1.10 & 1.05 & 1.08 & 1.00 \\
\hline & & $\mathrm{CoV}$ & 0.31 & 0.05 & 0.18 & 0.15 \\
\hline & \multirow{3}{*}{$\begin{array}{c}\mathrm{FE} \\
\text { models }\end{array}$} & $\mathrm{N}$ & 187 & 187 & 187 & 187 \\
\hline & & $\mu$ & 1.27 & 1.05 & 1.18 & 0.97 \\
\hline & & $\mathrm{CoV}$ & 0.59 & 0.02 & 0.50 & 0.22 \\
\hline & \multirow{2}{*}{ all data } & $\mu$ & 1.25 & 1.05 & 1.17 & 0.98 \\
\hline & & $\mathrm{CoV}$ & 0.56 & 0.03 & 0.46 & 0.21 \\
\hline \multirow{8}{*}{$\begin{array}{l}\text { distorti } \\
\text { onal } \\
\text { bucklin } \\
\mathrm{g}\end{array}$} & \multirow{3}{*}{ tests } & $\mathrm{n}$ & 22 & 22 & 22 & 22 \\
\hline & & $\mu$ & 0.987 & 1.04 & 1.06 & 1.01 \\
\hline & & $\mathrm{CoV}$ & 0.316 & 0.07 & 0.17 & 0.16 \\
\hline & \multirow{3}{*}{$\begin{array}{c}\text { FE } \\
\text { models }\end{array}$} & $\mathrm{n}$ & 187 & 187 & 187 & 187 \\
\hline & & $\mu$ & 1.19 & 1.10 & 1.07 & 1.08 \\
\hline & & $\mathrm{CoV}$ & 0.49 & 0.04 & 0.38 & 0.17 \\
\hline & \multirow{2}{*}{ all data } & $\mu$ & 1.17 & 1.09 & 1.07 & 1.08 \\
\hline & & $\mathrm{CV}$ & 0.47 & 0.04 & 0.36 & 0.17 \\
\hline
\end{tabular}

Note: $n=$ number of specimens used, $\mu=$ average, $\mathrm{CoV}=$ coefficient of variation

\section{Design parameterization for CFS member post-peak behavior}

No design guidance for post-peak behavior of CFS beams exists in current specifications. Here we investigate the use of cross-section slenderness $(\lambda)$ to predict post-peak parameters for the 
modified Type1 model, Figure 4. The maximum rotation $\left(\theta_{4}\right)$, post-peak yielding plateau $(\Delta \theta)$ and post-peak moment drop $(\Delta M)$ are all plotted versus the appropriate local or distortional cross-section slenderness in Figure 8. Although their correlations with cross-section slenderness are not as strong for post-peak parameters as pre-peak parameters, the trends are clear and utilized here for providing a simplified design model. In some cases limitations in the underlying test or simulation data (noting the presence of obvious outliers) also complicates these predictions. For example, the tests and simulations of [3-5] were not specifically intended for this work and in some cases termination at a given moment or rotation reflected practical testing or modeling limitations as opposed to problematic behavior in the beams. Nonetheless, simple design expressions are possible for $\theta_{4}, \Delta \theta$ and $\Delta M$ and illustrated graphically to compare with the available data in Figure 9 and their development is fully discussed in the following sections.

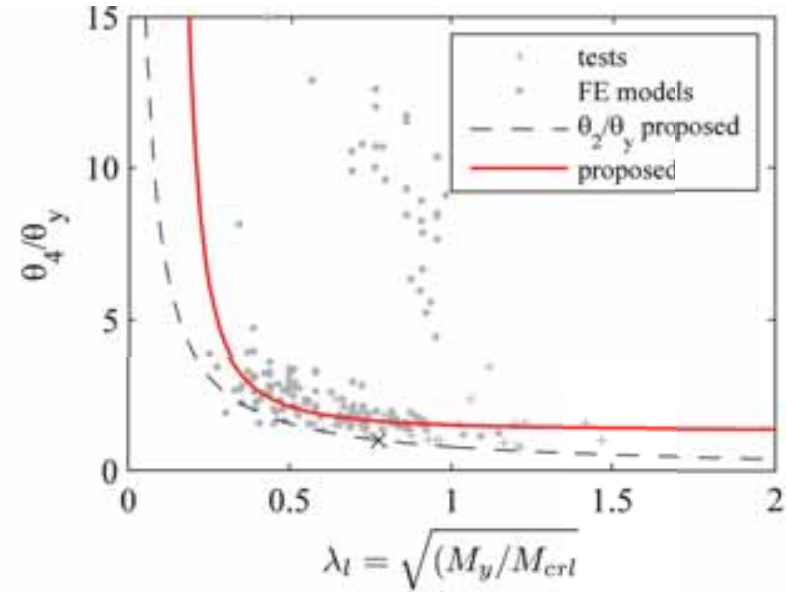

a. Maximum rotation vs. local slenderness

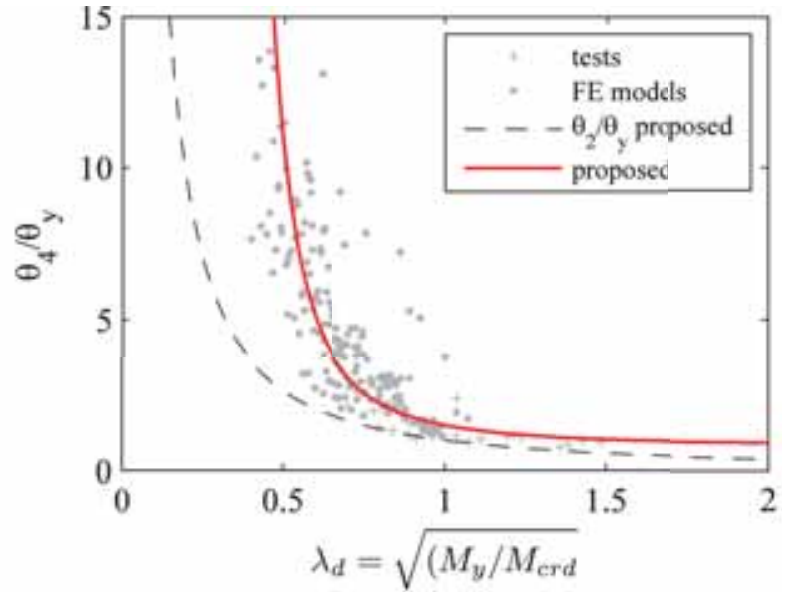

b. Maximum rotation vs. distortional slenderness 


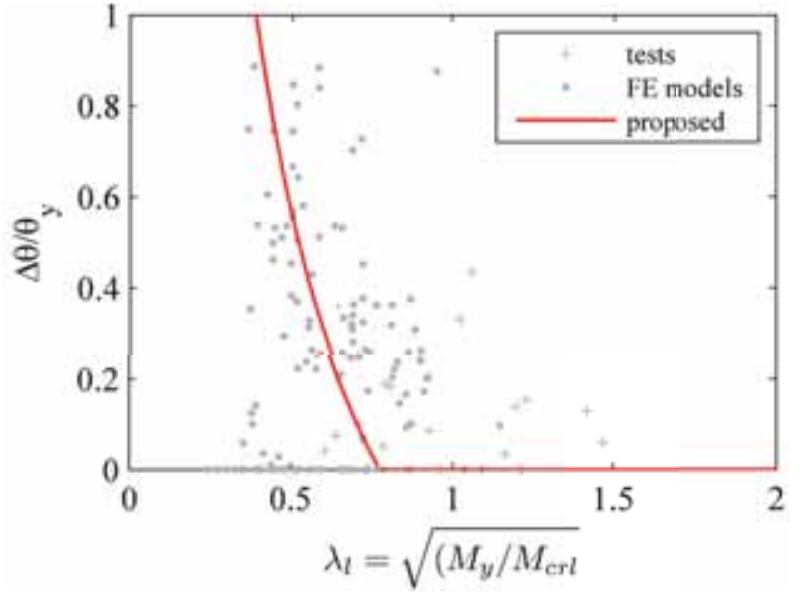

c. Post-peak yielding $(\Delta \theta)$ vs. local slenderness

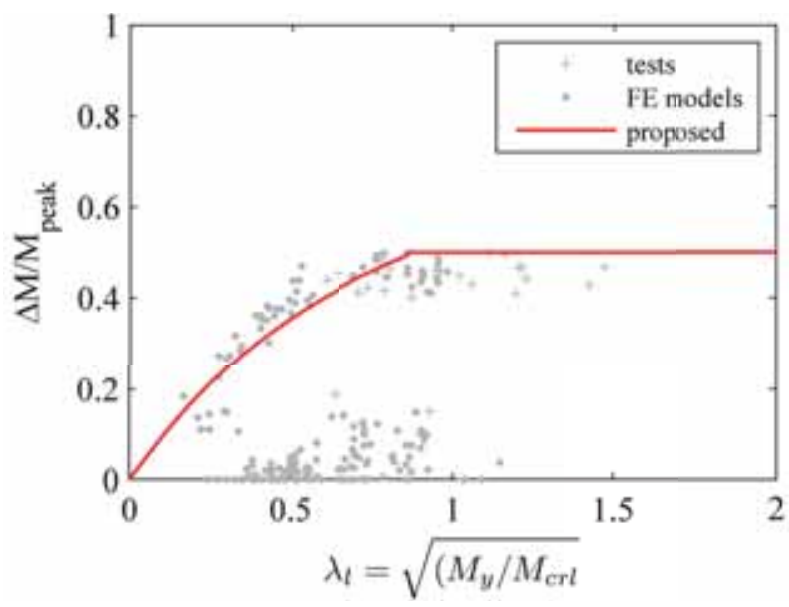

e. Post-peak moment drop $(\Delta \mathrm{M})$ vs. local slenderness (note $M_{\text {peak }}=M_{2}$ )

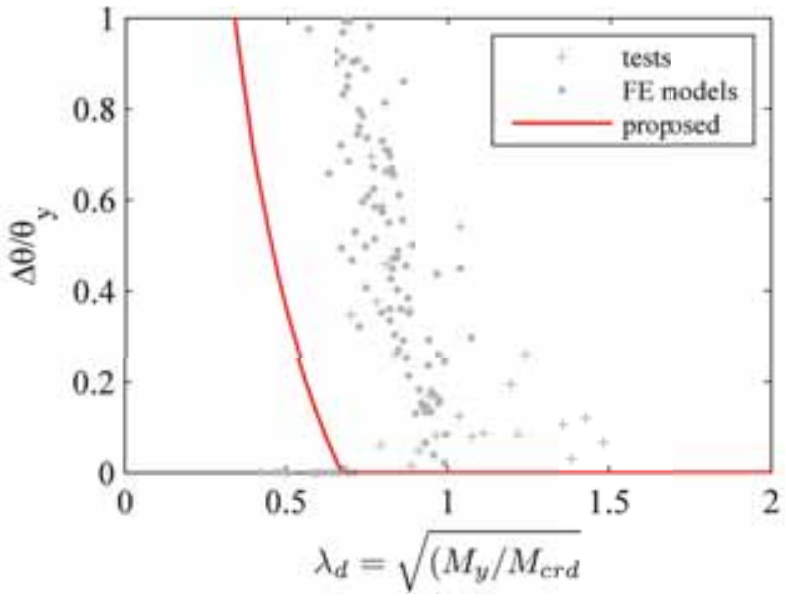

d. Post-peak yielding $(\Delta \theta)$ vs. distortional slenderness

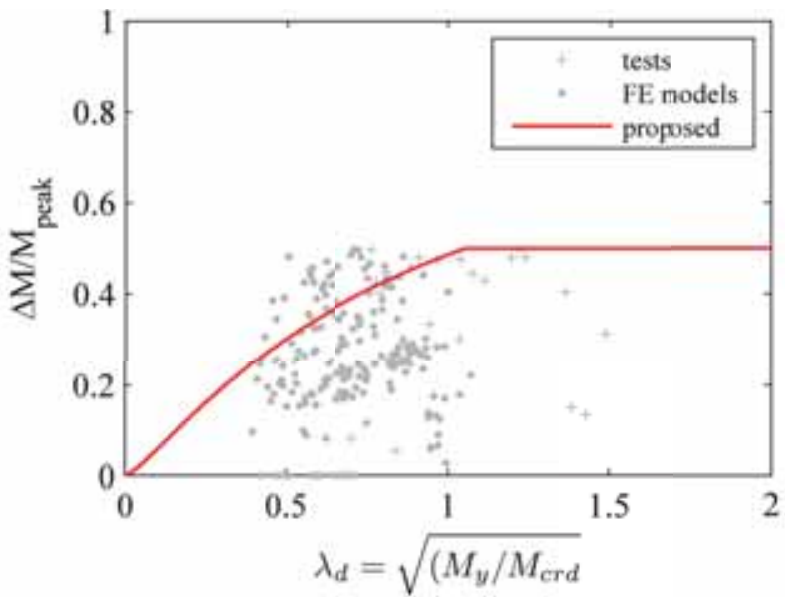

f. Post-peak moment drop $(\Delta \mathrm{M})$ vs. distortional slenderness (note $M_{\text {peak }}=M_{2}$ )

Figure 8. Parametrization of CFS beam post-peak behavior

\subsection{New design expressions for local buckling}

The post-peak performance has much greater scatter in the selected data than the peak and prepeak behavior. The existing limits as used in strength design; such as $\lambda_{1}=0.776$, were maintained for consistency even when fit to the data was poor. Otherwise simplified curves were fit such that they followed the trends of the data in an overall fashion. The resulting expressions are not 
unique and are thus judged based on their overall accuracy recognizing similar but different expressions may also work equally well. Based on Figure $8(\mathrm{a})$, it is proposed that $\theta_{4}$ for local buckling may be approximated as:

$$
\frac{\theta_{4}}{\theta_{y}}=\left\{\begin{array}{cl}
1.5 \frac{1}{\lambda_{\text {? }}} & \text { if } \lambda_{\text {? }}>1 \\
1.5\left(\frac{1}{\lambda_{\text {[? }}}\right)^{1 / 4 \lambda_{l}} & \text { if } \lambda_{\text {?] }} \leq 1
\end{array}\right\}
$$

This leaves the post-peak parameters $\Delta \theta$ and $\Delta M$ in need of prediction for local buckling. In general $\Delta \theta$ is intended to capture post-peak yielding, theoretically this is only significant for sections with inelastic reserve. The scatter is large in Figure 8(c) and many sections that have strength below $M_{\mathrm{y}}$ exhibit some post-peak yielding. However, for simplicity it is proposed that only sections with strength greater than $M_{\mathrm{y}}$ be predicted to have nonzero $\Delta \theta$. The following expressions are proposed for use and shown in Figure 8(c):

$$
\frac{\Delta \theta}{\theta_{y}}=\left\{\begin{array}{cl}
\left(\frac{0.776}{\lambda_{\text {? }}}\right)-1 & \text { if } \lambda_{\text {?] }}<0.776 \\
0 & \text { if } \lambda_{\text {?? }} \geq 0.776
\end{array}\right.
$$

Finally, the post-peak moment drop $(\Delta M)$ is explored. Note $(\Delta \theta,-\Delta M)+\left(\theta_{2}, M_{2}\right)=\left(\theta_{3}, M_{3}\right)$, so determination of $\Delta M$ is the final necessary parameter for the modified Type 1 model. The postpeak moment drop is provided as a function of local slenderness for the available data in Figure 8(e). For some of the data little or no moment drop is observed, this occurs in data where sufficient post-peak rotation was not explored (either the test or the FE model was stopped before reaching high post-peak rotations - this is a pronounced limitation of this existing data). Thus, 
the data with post-peak moment drop is the most important. In the absence of a definitive method it is presumed that a $50 \%$ moment drop exists for all sections with some local buckling strength reduction $\left(\lambda_{0}>0.776\right)$, otherwise the moment drop increases from zero as the local slenderness increases via:

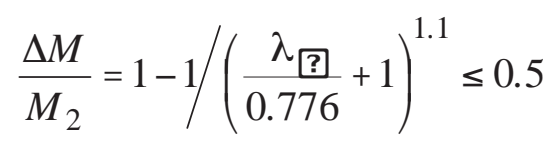

Observed and measured $M-\theta$ behavior of all the available local buckling data is provided in Figure 9 against the modified Type 1 model prediction method. For most of the FE models, Figure $9 \mathrm{~b}$, the $\Delta \theta$ prediction is large enough that little or no additional rotation exists after the post-peak moment drop $(\Delta M)$. The post-peak prediction provides an approximate and conservative prediction, better aligned with the experiments than with the FE models, but still a useful estimation of the $M-\theta$ behavior.

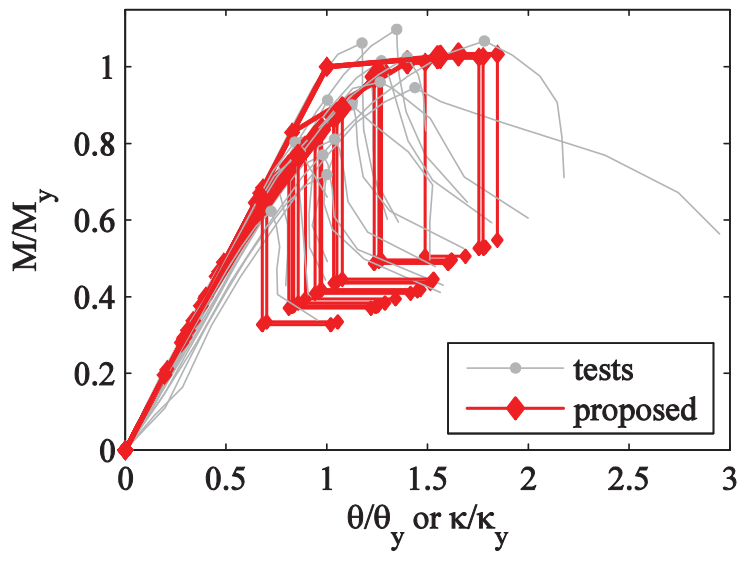

a. tests

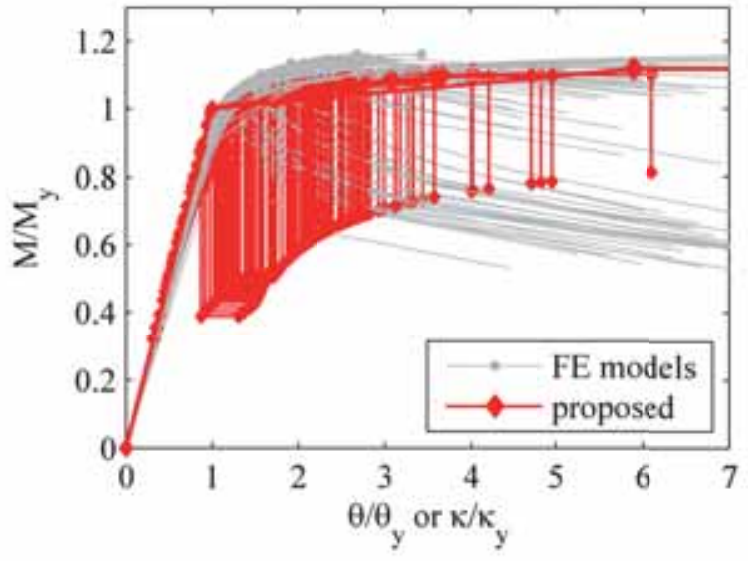

b. FE models

Figure 9. Moment-rotation behavior for local buckling data 


\subsection{New design expressions for distortional buckling}

Similar to local buckling, post-peak behavior is evaluated and predicted with new design expressions for distortional buckling. The post-peak parameters of the modified Type 1 model are captured in Figures $8 \mathrm{~b}, \mathrm{~d}$ and $\mathrm{f}$ and are arrived at in a similar fashion to the local buckling results. The maximum rotation $\left(\theta_{4}\right.$, Figure $\left.8 \mathrm{~b}\right)$ is set equal to 1.5 times the rotation at peak moment $\left(\theta_{2}\right)$ when $\lambda_{d}>1$, the same as in the local buckling case - this decision to limit the peak rotation in distortional buckling to be equal to local buckling is conservative and consistent with generally agreed understanding of post-peak response in local vs. distortional buckling, but the data does support allowing even larger rotations.

$$
\frac{\theta_{4}}{\theta_{y}}=\left\{\begin{array}{ll}
1.5\left(\frac{1}{\lambda_{d}}\right)^{1.4} & \text { if } \lambda_{d}>1 \\
1.5\left(\frac{1}{\lambda_{d}}\right)^{1.4 / \lambda_{d}} & \text { if } \lambda_{d} \leq 1
\end{array}\right\}
$$

The inelastic plateau ( $\Delta \theta$, Figure $8 \mathrm{~d}$ ) is only allowed for members predicted to have strength greater than $M_{y}$, and otherwise follows the available data as closely as possible.

$$
\frac{\Delta \theta}{\theta_{y}}=\left\{\begin{array}{cc}
\left(\frac{0.673}{\lambda_{d}}\right)-1 & \text { if } \lambda_{d}<0.673 \\
0 & \text { if } \lambda_{d} \geq 0.673
\end{array}\right.
$$

The moment drop expression ( $\Delta M$, Figure $8 \mathrm{f}$ ) follows the same basic expression as local buckling and assumes a 50\% drop in moment for sections which experience any reduction in strength due to distortional buckling (i.e., $M_{n d}<M_{y}, \lambda_{d}>0.673$ ). 


$$
\frac{\Delta M}{M_{2}}=1-1 /\left(\frac{\lambda_{d}}{0.673}+1\right)^{1.4} \leq 0.5
$$

In general, the distortional buckling expressions provide more conservative predictions than the local buckling expressions. This is, in part, intentional as existing strength expressions for distortional buckling are more conservative and it was decided to limit distortional buckling post-peak behavior to be equal to or more conservative than local buckling for a given level of slenderness. Figure 10 provides the observed post-peak $M-\theta$ behavior of all available test and FE model data, as well as their predictions with the newly proposed method. Similar to the local buckling data, the new predictions provide a useful representation of post-peak behavior, but are conservative for sections with inelastic reserve.

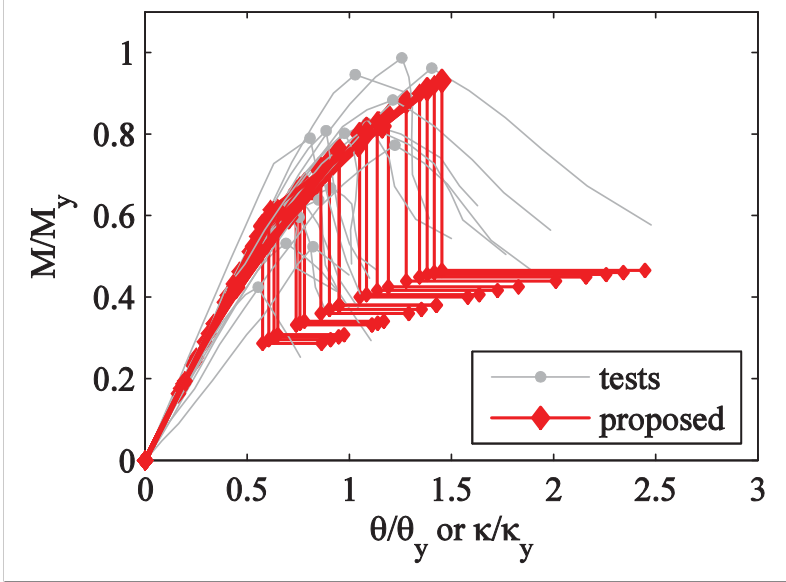

a. tests

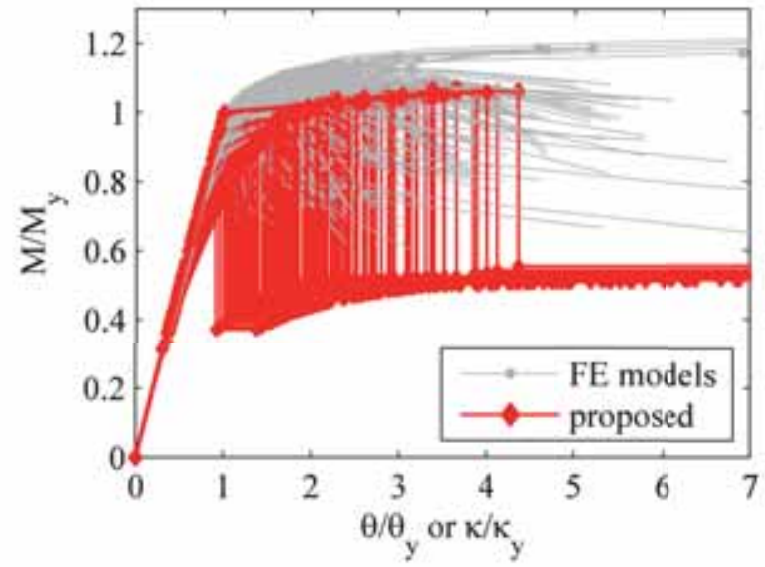

b. FE models

Figure 10. Moment-rotation behavior for distortional buckling data

\subsection{Post-peak predicted response: $M_{3}$ and $\theta_{3}$}

Based on the developed expressions the proposed moment drop allows one to obtain $M_{3}$, the post-peak design moment for the modified Type 1 model (Figure 4). 


$$
M_{3}=M_{2}-\Delta M
$$

The relation between the peak moment and post-peak design moment predictions and crosssection slenderness are shown in Figure 11 for local and distortional buckling. The post-peak performance has greater scatter in the observed data than the peak behavior. Accordingly, the $M_{3} /$ $M_{2}$ ratio varies across cross-section slenderness, but still follows reasonable (albeit lowerbound) trends.

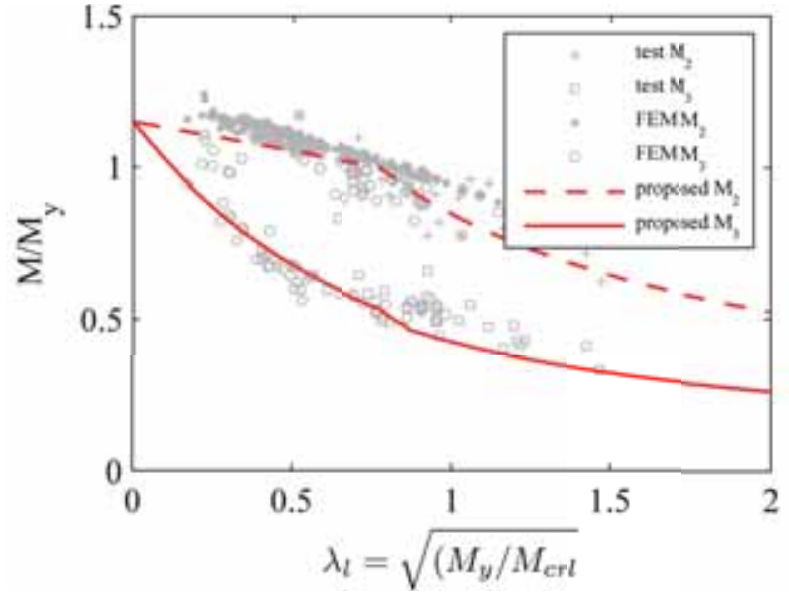

a. comparison of $M_{2}$ and $M_{3}$ predictions vs. local slenderness

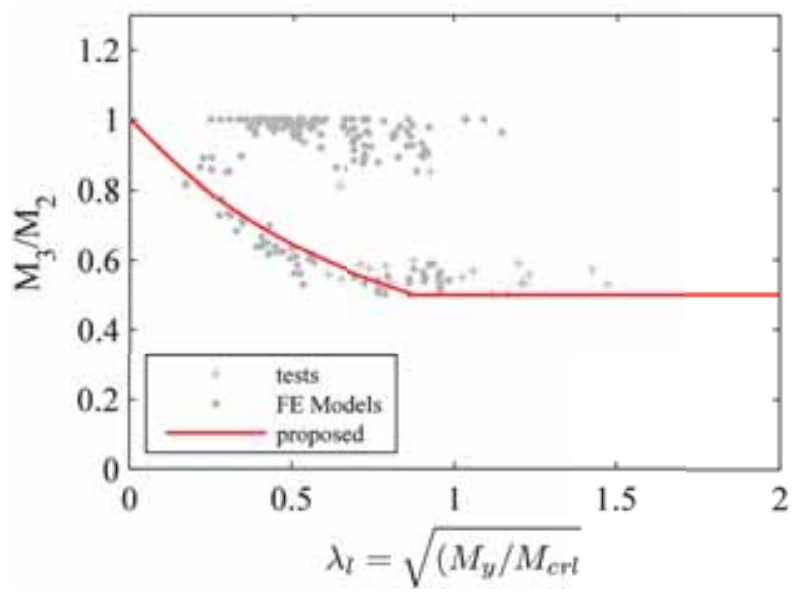

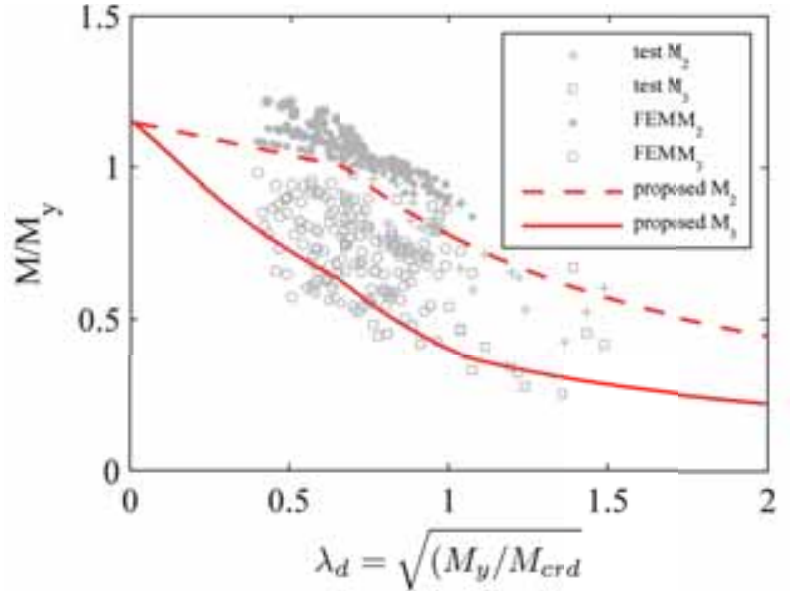

b. comparison of $M_{2}$ and $M_{3}$ predictions vs. distortional slenderness

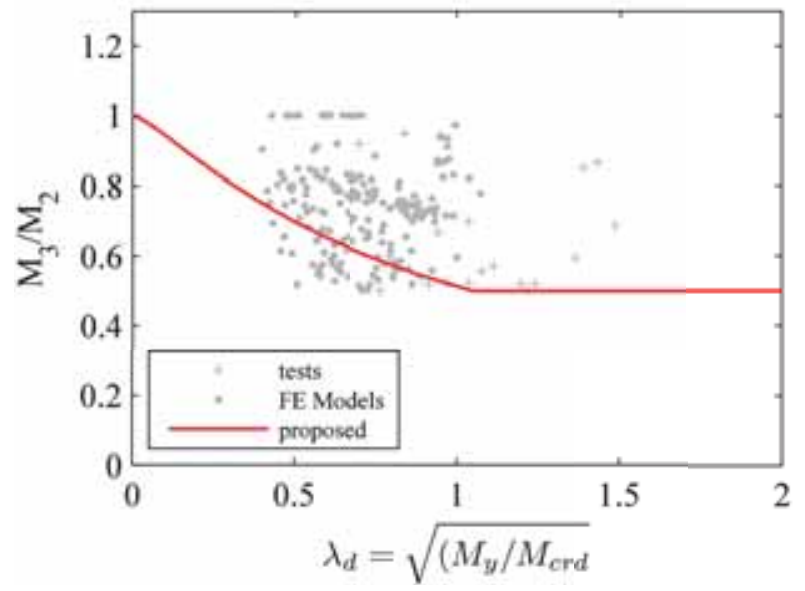



c. relationship between $M_{2}$ and $M_{3}$ vs. local
d. relationship between $M_{2}$ and $M_{3}$ vs. slenderness distortional slenderness

Figure 11. Accuracy of $M_{3}$ prediction with proposed method

Similarly, the post-peak design rotation, $\theta_{3}$, can be calculated using the post-peak rotation step prediction.

$$
\theta_{3}=\theta_{2}+\Delta \theta \leq \theta_{4}
$$

Comparisons of $\theta_{3}$ predictions are provided in Figure 12. The scatter for $\theta_{3}$ prediction is large especially for the local buckling data and the $\theta_{3}$ prediction trends conservatively, as expected, for distortional buckling data. However, the overall accuracy and simplicity of the prediction method is intended to make the new expressions useful in a design context.

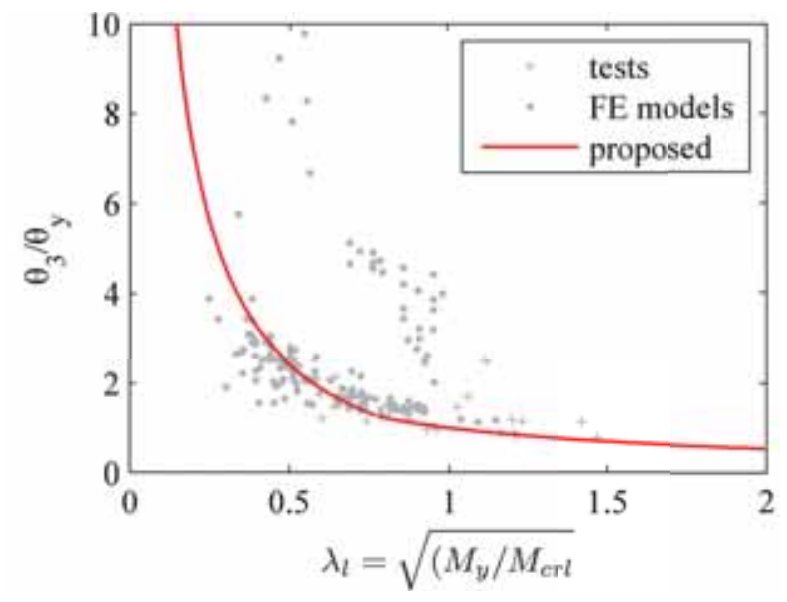

a. local buckling

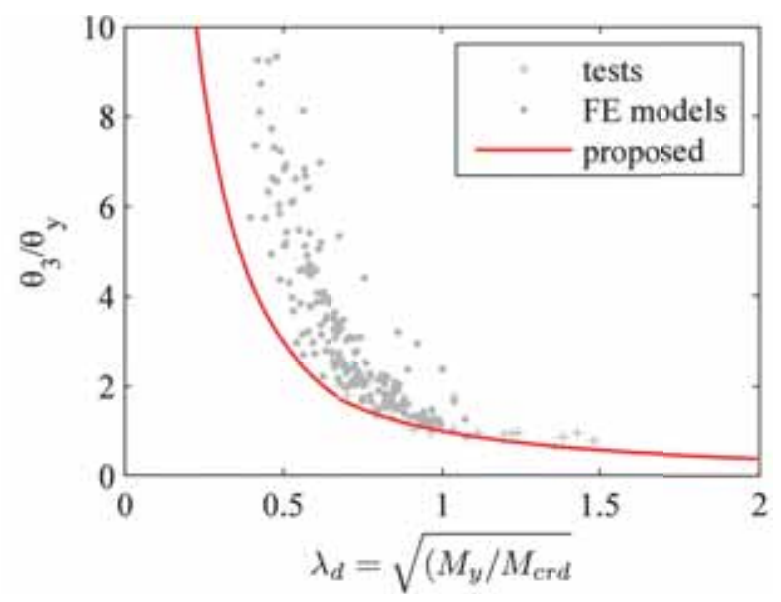

b. distortional buckling

Figure 12 . Accuracy $\theta_{3}$ prediction with the new method

\subsection{Accuracy of post-peak predictions: post-peak energy and $\theta_{4}$}


A quantitative assessment of the accuracy of the new prediction method is provided in Table 3. The pre-peak model fits well, while the post-peak is a simplified approximation that equates energy up to $50 \%$ of peak $\left(M_{3}, \theta_{4}\right)$ and conservatively terminates post-peak response at $\theta_{4}$. Moreover, some of the FE models provided extremely large deformation capacity. Models having rotational capacity equal to or less than $6 \theta_{\mathrm{y}}$ are considered for the statistical comparison. This upper limit is motivated from the upper limit on the modelling parameters for compact hotrolled steel beams in ASCE41 [10]. The mean and standard deviation of observed-to-predicted ratios of post-peak energy, maximum rotation capacity, and post-peak moment $M_{3}$, are calculated for the selected tests and FE models. Consistent with the figures, the results are systematically conservative. The mean of observed-to-predicted ratio is generally high since the measured postpeak data has less reliability. The variation (standard deviations) are significant; however, taken in total the method provides the first guidance on how to rationally predict post-peak behavior.

Table 3. Test-to-predicted statistics for the post-peak predictions

\begin{tabular}{|c|c|c|c|c|c|}
\hline & & & \multicolumn{3}{|c|}{ ratios of observed-to-predicted for } \\
\hline & & & $\begin{array}{c}\text { Post-peak } \\
\text { energy }\end{array}$ & $\theta_{4}$ & $\mathrm{M}_{3}$ \\
\hline \multirow{8}{*}{$\begin{array}{c}\text { local } \\
\text { bucklin } \\
\mathrm{g}\end{array}$} & \multirow{3}{*}{ tests } & $\mathrm{n}$ & 22 & 24 & 24 \\
\hline & & $\mu$ & 2.78 & 1.41 & 1.24 \\
\hline & & $\mathrm{CoV}$ & 0.70 & 0.39 & 0.20 \\
\hline & \multirow{3}{*}{$\begin{array}{c}\mathrm{FE} \\
\text { models }\end{array}$} & $\mathrm{n}$ & 114 & 124 & 124 \\
\hline & & $\mu$ & 3.23 & 1.11 & 1.83 \\
\hline & & $\mathrm{CoV}$ & 1.05 & 0.32 & 0.09 \\
\hline & \multirow{2}{*}{ all data } & $\mu$ & 3.15 & 1.16 & 1.74 \\
\hline & & $\mathrm{CoV}$ & 0.99 & 0.33 & 0.11 \\
\hline
\end{tabular}




\begin{tabular}{|c|c|c|c|c|c|}
\hline \multirow{8}{*}{$\begin{array}{l}\text { distorti } \\
\text { onal } \\
\text { bucklin } \\
\mathrm{g}\end{array}$} & \multirow{3}{*}{ tests } & $\mathrm{n}$ & 22 & 22 & 22 \\
\hline & & $\mu$ & 1.26 & 0.94 & 1.26 \\
\hline & & $\mathrm{CoV}$ & 1.04 & 0.40 & 0.31 \\
\hline & \multirow{3}{*}{$\begin{array}{c}\mathrm{FE} \\
\text { models }\end{array}$} & $\mathrm{n}$ & 127 & 136 & 136 \\
\hline & & $\mu$ & 2.58 & 1.13 & 1.65 \\
\hline & & $\mathrm{CoV}$ & 0.67 & 0.34 & 0.18 \\
\hline & \multirow{2}{*}{ all data } & $\mu$ & 2.39 & 1.11 & 1.60 \\
\hline & & $\mathrm{CoV}$ & 0.72 & 0.51 & 0.20 \\
\hline
\end{tabular}

Note: $n=$ number of specimens used, $\mu=$ average, $\mathrm{CoV}=$ coefficient of variation

\section{Discussion}

Cold-formed steel beams are unique in that their moment-rotation response may be driven by geometric nonlinearity, material nonlinearity, or a strong combination of both. Thus, simplified expressions that aim to assist in predicting this behavior must be capable of spanning these regimes. The developed design expressions are provided for local buckling at three different local buckling cross-section slenderness values ranging from slender to stocky in Figure 13. The predicted moment-rotation response demonstrates how a slender beam (Figure 13a) has reduced pre-peak rigidity due to local buckling and has highly limited post-peak reserve, while a typical beam at an intermediate slenderness value (Figure 13b) has elastic pre-peak response for larger rotations before inelastic local buckling limits capacity and post-peak response. Finally, for a stockier CFS beam (Figure 13c) the response is more akin to compact hot-rolled steel sections with the modification that the reduced rigidity developed between first yield and the peak moment (approaching $M_{\mathrm{p}}$ ) is accounted for and a post-peak yielding plateau is also present depending on the slenderness. The large moment drop that is built into the expressions is 
conservative and may require revisiting in the future depending on system-level sensitivity to this assumption; however as the first method of this kind it was decided to adopt a lowerbound approach to the available data.

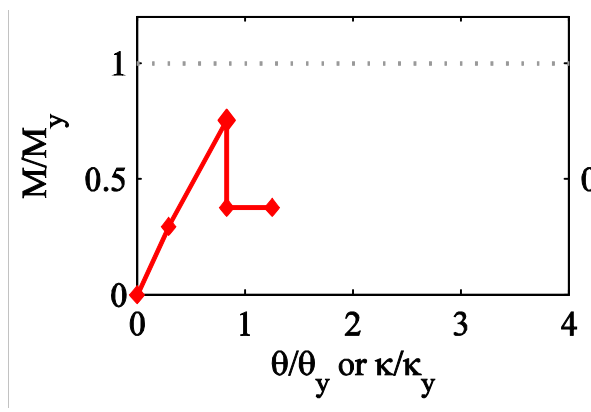

a. $\lambda_{1}=1.200$

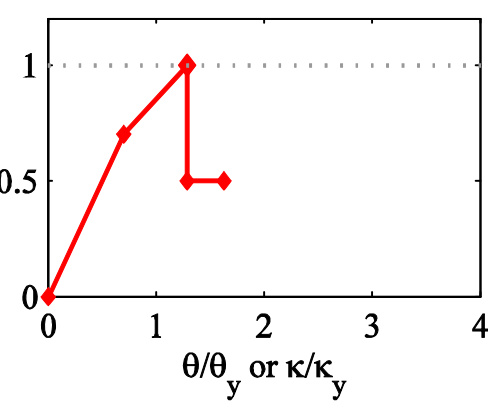

b. $\lambda_{1}=0.776$

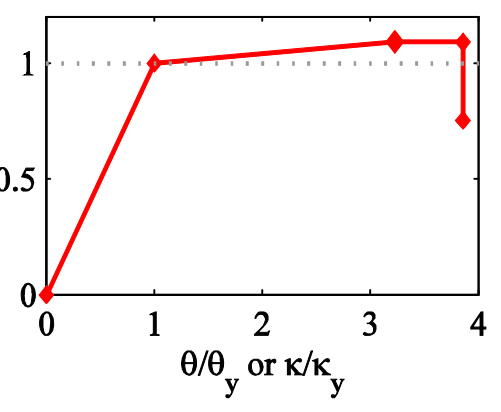

c. $\lambda_{1}=0.310$

Figure 13. Realized local buckling $M-\theta$ or $M$ - $\kappa$ backbone curves from proposed design expressions as a function of cross-section slenderness

The ability of CFS structures to absorb deformation (energy) is derived by all of its components: members, connections, sheathing, etc. Beams are traditionally a fundamental building block in building up an assessment of a system's ability to absorb energy. The results of this research show that in-plane behavior of beams can be predicted with design expressions depending on cross-section slenderness. Consequently, laterally-braced beams under monotonic loads have been studied here to parametrize beam behavior for local and distortional buckling failure modes. Additional work remains to account for out-of-plane behavior (i.e. interaction with lateraltorsional buckling) and to account for cyclic degradation. In addition, application of the developed expressions within the ASCE 41 framework, including the development of appropriate $m$ factors for linear static analysis methods remain. 


\section{Conclusion}

Knowledge of the moment-rotation $(M-\theta)$ response of cold-formed steel beams is fundamental to the success of cold-formed steel structures. Existing data from monotonic tests and finite element models provide a characterization of the backbone $M-\theta$ response of cold-formed steel beams failing in local and distortional buckling limit states and spanning from slender to stocky. Simplified multi-linear models in the spirit of ASCE 41 formulations are fit to existing data by insuring pre-peak and post-peak energy balance is maintained between the model and the original data. The derived model parameters, e.g. the moment at which pre-peak nonlinear stiffness engages $\left(M_{1}\right)$ or the available rotation at a post-peak moment level $50 \%$ of the peak value $\left(\theta_{4}\right)$ are then examined to determine if a simple method may be used in their prediction. It is found that local and distortional cross-sectional slenderness are adequate explanatory variables for characterizing the beam behavior - and simple design expressions are developed for predicting a unique $M-\theta$ curve for all cold-formed steel cross-sections failing in local or distortional buckling and spanning from slender to stocky. The developed expressions are shown to adequately predict the available data and provide a means to predict the degradation of prepeak flexural rigidity with the reduced moment of inertia. In addition, for the first time, postpeak predictions of $M-\theta$ behavior including post-peak moment degradation are available for cold-formed steel beams. The research demonstrates the viability of a significant expansion of the Direct Strength Method philosophies to the prediction of post-peak member behavior and provides a tool for exploring the nonlinear response of cold-formed steel systems. 


\section{Acknowledgement}

This paper was prepared from the study as part of the U.S. National Science Foundation sponsored CFS-NEES project [15]: NSF-CMMI-1041578: NEESR-CR: Enabling PerformanceBased Seismic Design of Multi-Story Cold-Formed Steel Structures. The project also received supplementary support and funding from the American Iron and Steel Institute. Project updates are available at www.ce.jhu.edu/cfsnees. Any opinions, findings, and conclusions or recommendations expressed in this publication are those of the author(s) and do not necessarily reflect the views of the National Science Foundation, nor the American Iron and Steel Institute.

\section{References}

1. AISI-S100-07 (2012). North American Specification for the Design of Cold-Formed Steel Structural Members, 2012 edition. American Iron and Steel Institute, Washington, D.C.

2. AISI-S100-07 (2012). Supplement 2012 to the North American Specification for the Design of Cold-Formed Steel Structural Members, 2012 edition, Appendix 1, Design of ColdFormed Steel Structural Members Using Direct Strength Method. American Iron and Steel Institute, Washington, D.C.

3. Yu, C., Schafer, B.W. (2003). Local buckling Test on Cold-Formed Steel Beams. Journal of Structural Engineering. ASCE, Vol. 129, No. 12, pp. 1596-1606.

4. Yu, C, Schafer, B.W. (2006). Distortional buckling tests on cold formed steel beams. Journal of Structural Engineering, ASCE, Vol. 132, No. 4, pp. 515-528.

5. Shifferaw Y., Schafer, B.W. (2012). Inelastic bending capacity in cold-formed steel members. Journal of Structural Engineering, Vol. 138, No. 4, pp. 468-480.

6. ABAQUS (2007). ABAQUS/Standard User's Manual, Version 6.9, ABAQUS, Inc., Pawtucket, RI.

7. Ayhan, D., Schafer, B.W. (2015). Cold-formed steel member bending stiffness prediction. Journal of Constuction and Steel Research (JSCR), doi: 10.1016/j.jcsr.2015.07.004.

8. Park, R. (1988). Ductility Evaluation from Laboratory and Analytical Testing.9th World Conference on Earthquake Engineering, Tokyo-Kyoto, Japan, Vol.VIII.

9. Ayhan, D., Schafer, B.W. (2011). Impact of cross-section stability on cold-formed steel member stiffness and ductility. Annual Stability Conference, Structural Stability Research Council, Pittsburgh, PA, USA, May 10-14.

10. ASCE/SEI 41-13 (2013). Seismic Rehabilitation of Existing Buildings, American Society of Civil Engineers, Reston, Virginia.

11. FEMA 273 (1997) NEHRP Guidelines for the seismic rehabilitation of buildings. Federal Emergency Management Agency, Building Seismic Social Council (BSSC), Washington, D.C. 
12. FEMA 356 (2007) Prestandard and Commentary for the seismic rehabilitation of buildings. Federal Emergency Management Agency, American Society of Civil Engineers (ASCE), Washington, D.C.

13. Ayhan, D. (2013). Collapse characterization of cold-formed steel beams, Ph.D. Thesis, Istanbul Technical University, Istanbul, Turkey.

14. MATLAB (2009). Version 7.9.0.529, The MathWorks Inc.

15. Schafer BW, Ayhan D, Leng J, Liu P, Padilla-Llano D, Peterman KD, Stehman M, Buonopane SG, Eatherton M, Madsen R, Manley B, Moen CD, Nakata N, Rogers C, Yu C. (2014). The CFS-NEES effort: Advancing Cold-Formed Steel Earthquake Engineering. Proceedings of the 10th National Conference in Earthquake Engineering, Earthquake Engineering Research Institute, Anchorage, AK. 